\title{
Transportation Cost Minimization: Max Min Penalty Approach
}

\author{
S.Rekha, B.Srividhya \& S.Vidya \\ Dept. of Mathematics, Dr.SNS Rajalakshmi college of Arts \&Science, Coimbatore-49, TamilNadu,India
}

\begin{abstract}
In this paper, a transportation problem is applied to determine the reduction in Transportation cost (TC) of tools which appeared to be an important component of the total cost of production. The algorithm determines the Initial Basic Feasible(IBFS) Solution of Transportation Problem (TP) to minimize the cost. The result with an elaborate illustration demonstrates that the method presented here is effective in minimizing the transportation cost.
\end{abstract}

Keywords: Transportation ,Minimization cost, maxmin penalty cost,VAM, sources, destination

\section{INTRODUCTION}

Transportation model has an increasingly great impact on the management of transport. It is one of the subclass of linear programming problem, it aims to transport various quantities of a single homogeneous commodity, that are initially stored at various source to different destination in such that the transportation cost, transportation distance or time is minimum. There are two main responsible for the development of transportation model which involve a number of shipping sources and number of destinations[2]. It deal with the minimum cost plan to transport a commodity from a number of sources to destinations using initial feasible solution max min penalty approach .Methods are available to determine the IBFS. The well-known methods are: Vogel's Approximation Method (VAM) [1], Balakrishnan's version of VAM [6],H.H.shore version of VAM[7]. In this paper we present a method which gives same minimization cost as Vogel approximation method .

\section{ALGORITHM OF THE MAX MIN PENALTY APPROACH:}

Step 1 :Examine whether the total supply equals total demand .If not introduce dummy row/column

Step $2: T$ he first brackets, which are the difference of the greatest element and smallest element of each row and column of the TT.

Step 3: Identify the largest distribution. Choose the smallest entry along the largest distribution. If there are two or more smallest elements, choose any one of them arbitrarily.

Step 4 : Allocate $\mathrm{x} i \mathrm{j}=\min (\mathrm{a} \mathrm{i}, \mathrm{b} \mathrm{j})$ on the left top of the smallest entry in the cell $(\mathrm{i}, \mathrm{j})$ of the TT.

Step 5: Recomputed the column and row difference for the reduce transportation table and go to step 4 . Repeat the procedure until all the rim satisfied.

III . ILLUSTRATION

\begin{tabular}{|c|l|l|l|l|l|}
\hline & A & B & C & D & Supply \\
\hline P & 21 & 16 & 25 & 13 & 11 \\
\hline Q & 17 & 18 & 14 & 23 & 13 \\
\hline R & 32 & 27 & 18 & 41 & 19 \\
\hline Demand & 6 & 10 & 12 & 15 & \\
\hline
\end{tabular}

Solution :

Using VAM method,

Since, $\Sigma a_{i}=\Sigma b_{j}=43$, the given transportation problem is balanced . $\therefore$ There exists a basic feasible solution to this problem.

By Vogel's approximation method, the initial solution is as shown in the following table

\begin{tabular}{|c|c|c|c|}
\hline 21 & 16 & 25 & $\begin{array}{ll}13 & \\
& 11\end{array}$ \\
\hline $\begin{array}{r}17 \\
6\end{array}$ & $\begin{array}{ll}18 & \\
& 3\end{array}$ & 14 & $\begin{array}{ll}23 & \\
& 4\end{array}$ \\
\hline 32 & $\begin{array}{ll}27 & \\
& 7\end{array}$ & 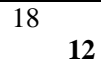 & 41 \\
\hline
\end{tabular}

\begin{tabular}{|l|l|l|l|}
\hline$(1)$ & $\ldots \ldots$. & $\ldots \ldots$ & $\ldots \ldots$ \\
\hline$(3)$ & $(3)$ & $(3)$ & $(4)$ \\
\hline$(9)$ & $(9)$ & $(9)$ & $(9)$ \\
\hline
\end{tabular}

\begin{tabular}{|l|l|l|l|}
\hline$(4)$ & $(2)$ & $(4)$ & $(10)$ \\
\hline$(15)$ & $(9)$ & $(4)$ & $(18)$ \\
\hline$(15)$ & $(9)$ & $(4)$ & $\ldots \ldots$. \\
\hline$\ldots \ldots \ldots .$. & $(9)$ & $(4)$ & $\ldots \ldots$ \\
\hline
\end{tabular}


That is

\begin{tabular}{|ll|ll|ll|ll|}
\hline 21 & & \multicolumn{2}{|l|}{16} & 25 & & 13 & \\
& & & & & & 11 \\
\hline 17 & & 18 & & 14 & & 23 & \\
& 6 & & 3 & & & & 4 \\
\hline 32 & & 27 & & 18 & & 41 & \\
& & & 7 & & 12 & & \\
\hline
\end{tabular}

From this table, we see that the number of non-negative independent allocations is $(m+n-1)=(3+4-1)=6$. Hence the solution is non-degenerate basic feasible .

$\therefore$ The initial transportation cost

$=$ Rs. $13 \times 11+17 \times 6+18 \times 3+23 \times 4+27 \times 7+18 \times 12$

$=$ Rs.796/-

\section{ILLUSTRATION}

Using max min penalty Approach ,the initial basic feasible solution as follows:

Step 1 : Examine whether the total supply equals total demand is 43 .

Step 2 :The first brackets, which are the difference of the greatest element and smallest element of each row and column of the TT.

Step 3 :Identify the largest distribution(28) in a column . Choose the smallest entry along the largest distribution is 13 . If there are two or more smallest elements, choose any one of them arbitrarily.

Step 4: Allocate $\mathrm{x} 14=\min (11,15)=11$ on the left top of the smallest entry in the cell $(1,4)$ of the TT.

Step 5:Recomputed the column and row difference for the reduce transportation table and go to step 4 .Repeat the procedure until all the rim satisfied.

\begin{tabular}{|c|c|c|c|c|c|c|c|c|c|}
\hline & $\mathrm{A}$ & $\mathrm{B}$ & $\mathrm{C}$ & $\mathrm{D}$ & supply & \multicolumn{4}{|c|}{ Row penalty indicators } \\
\hline $\mathrm{P}$ & 21 & 16 & 25 & 13 & 11 & (12) & - & - & - \\
\hline $\mathrm{Q}$ & 17 & 18 & 14 & 23 & 13 & $(9)$ & $(9)$ & $(6)$ & (1) \\
\hline $\mathrm{R}$ & 32 & 27 & 18 & 41 & 19 & (23) & (23) & (14) & (5) \\
\hline demand & 6 & 10 & 12 & 15 & & & & & \\
\hline \multirow{4}{*}{$\begin{array}{l}\text { Column } \\
\text { penalty } \\
\text { indicators }\end{array}$} & (15) & (11) & (11) & (28) & & & & & \\
\hline & $(15)$ & $(9)$ & $(4)$ & $(18)$ & & & & & \\
\hline & $(15)$ & $(9)$ & - & (18) & & & & & \\
\hline & $(15)$ & $(9)$ & - & - & & & & & \\
\hline
\end{tabular}

\begin{tabular}{|c|c|c|c|}
\hline 21 & 16 & 25 & $\begin{array}{ll}13 & \\
& 11\end{array}$ \\
\hline $\begin{array}{ll}17 & \\
& 6\end{array}$ & $\begin{array}{ll}18 \\
& 3\end{array}$ & 14 & \begin{tabular}{|ll}
23 & \\
& 4
\end{tabular} \\
\hline 32 & $\begin{array}{ll}27 & \\
& 7\end{array}$ & $\begin{array}{ll}18 & \\
& \mathbf{1 2}\end{array}$ & 41 \\
\hline
\end{tabular}

From this table, we see that the number of non-negative independent allocations is $(m+n-1)=(3+4-1)=6$. Hence the solution is non-degenerate basic feasible .

$\therefore$ The initial transportation cost

$=$ Rs. $13 \times 11+17 \times 6+18 \times 3+23 \times 4+27 \times 7+18 \times 12$

$=$ Rs.796/-

\section{Optimal test:}

To find the optimal test for IBFS max min penalty approach

Since all dij $>0$ the solution under the test is optimal

\begin{tabular}{|c|c|c|c|}
\hline $\begin{array}{rr}21 & 7 \\
& 14 \\
\end{array}$ & $\begin{array}{ll}16 & 8 \\
& \\
& 8\end{array}$ & $\begin{array}{ll}25 & -1 \\
& 26 \\
\end{array}$ & $\begin{array}{ll}13 & \\
& 11\end{array}$ \\
\hline $\begin{array}{ll}17 & \\
& 6\end{array}$ & $\begin{array}{ll}18 \\
& 3\end{array}$ & $\begin{array}{ll}14 & 9 \\
& 5\end{array}$ & $\begin{array}{ll}23 & \\
& 4\end{array}$ \\
\hline $\begin{array}{ll}32 & 26 \\
& 6\end{array}$ & $\begin{array}{ll}27 & \\
& 7\end{array}$ & $\begin{array}{|ll|}18 & \\
& \mathbf{1 2}\end{array}$ & $\begin{array}{ll}41 & 32 \\
& \\
& 9\end{array}$ \\
\hline
\end{tabular}




\section{CONClusion}

The max min penalty approach are quite simple from the computational point of view and also, easy to understand and apply. The method presented and discussed above gives us an initial basic feasible solution of the transportation problem with equal constraints, in minimization cost and an alternative method of VAM. The method developed here ensures a solution which is very closer to the optimal solution.

\section{Reference:}

[1] Hamdy, T. Operations Research- An Introduction (Sixth Edition). Pearson Education Inc, 2002.

[2] Taha. H.A., Operations Research- Introduction, Prentice Hall of India (PVT), New Delhi, 2004.

[3] R. Gupta, Time-Cost Transportation Problem, Econ-math overview, 4(1977), 431-443.

[4] Sharma. J.K., Operations Research-Theory and applications, Macmillan India (LTD), New Delhi, 2005

[5]. R.R.K. Sharma and S. Prasad, Obtaining a good primal solution to the Uncapacitated Transportation Problem, European Journal of Operation Research, 122 (2000) 611-624.

[6] N. Balakrishnan, Modified Vogels Approximation Method for Unbalance Transportation Problem, Applied Mathematics Letters, 3(2) (1990) 9-11.

[7] H.H. Shore, The Transportation Problem and the Vogels Approximation Method, Decision Science 1(3-4) (1970) 441-457.. 